\title{
準剛体回転流中の微粒子分級のスケール則
}

\section{Scaling Law of Fine Particle Classification by Almost Rigidly Rotating Flow}

\author{
中林 功一, 土田 陽一 \\ Koichi NAKABAYASHI, Yoichi TSUCHIDA
}

\begin{abstract}
Scaling law of fine particle classification by a centrifugal system was studied in the present work. The centrifugal system accurately classifies fine particles suspended in a liquid (water) at a low concentration by applying an almost rigidly rotating through - flow between the housing - and core walls of a rotating double-walled container. We performed calssification experiments under various conditions by changing classifier size, feeder, true relative density and size of feed powders, and Ekman and Rossby numbers. Consequently, we found that the scaling law is such that the ratio of cut- off size to the length scale of the fluid or particle motion (characteristic length of the classifier) is determined as a function only of the centrifugal-effect parameter which is the ratio of centrifugal force to drag force exerting on a particle.
\end{abstract}

Key Words : Wet-type Centrifugal Classification, Almost Rigid Rotation, Cut Size, Scale Up, Particle Motion

\section{1. 緒言}

半導体産業をはじめとする先端技術分野を支える IC 基板や液晶ディスプレイ材料分野では，その材料 特性を高度化・高機能化するために，原料粉体粒度の 均一化とサブミクロン化の要求が非常に大きく，今後 なお一層この要求が強まる傾向にある。このような高 精度の微粒子分級に適合する方式を開発するために は，分級の流れ場中に乱れのない条件に加え，遠心力 を適宜自在に調節できるような分級の流れ場を作り出 す必要がある。そこで, 著者らは八ウジングとコアか らなる回転二重容器内の準剛体回転流を微粒子分級場 に応用する精密湿式遠心分級方式を開発した。そし て，コアが円柱面と球面，八ウジングが球面からなる 形状（円柱・球形状と呼ぶ）の場合についてバッチ式 と連続式の分級実験を行い, その結果, 両者の場合之 もに当初の予想以上に良好な分級精度が得られること が分かった 21.

一方，この方式の分級機で産業界の要望を満足させ るための性能を実現するためには, 種々改善すべき問

2000 年 6 月 27 日受付

名古屋工業大学機械工学科

（テ466-8555 名古屋市昭和区御器所町）TEL 052-735-5323

Department of Mechanical Engineering,

Nagoya Institute of Technology

(Gokiso-cho, Showa-ku, Nagoya 466-8555)
題点が多く残っていることが明らかになった。これら の問題点を解決するためには，まず，分級径は何によ って決まるのかという分級径に対するスケール則を明 らかにしておく必要がある。準剛体回転流を応用した 分級方式についてのスケール則の研究はむろんない が，従来の分級機に対するものについてもスケール則 としてまとめられた研究は見当たらない。ただし，遠 心式空気分級機およびサイクロンについては，スケー ルアップ性能の観点からの考察がある ${ }^{3 \sim 5)}$ が, 無次元 パラメータを用いて十分明瞭な統一的に理解できるよ うなスケール則とはなっていない。

そこで, 本報では準剛体回転流によるバッチ式分級 方式を対象として, 分級機の代表長さ, 重力の方向に 対する回転軸の方向, 原料粉体の真比重, 粒度分布お よび供給方法が相違する種々の実験条件で分級試験を 行う。そして，粒子運動方程式に基づく理論的考察か ら，粒子運動を支配する最も重要な無次元パラメー夕 を求め，それにより実験デー夕を整理して，準剛体回 転流による分級方式におけるスケール則を明らかにす る。

\section{2. 分級試験とその結果}

\section{1 試験装置の形状と試料粉体}

Table 1 は，本研究および既報1)で用いた幾何学的 に相似な分級場の形状（円柱・球形状）をもつ 3 種類 
Table 1 Three kinds of geometrically similar sphere-cylinder classifiers, A (Fig. 1), B (Fig. 2), and $\mathrm{C}^{1)}$, and four kinds of feed powder, silica S (SS), silica M (SM), silica L (SL), and polymethyl methacrylate $(\mathrm{PM})^{1)}$, used in the present and pervious ${ }^{1)}$ studies

\begin{tabular}{|c|c|c|c|c|}
\hline Classifier & A & \multicolumn{2}{|c|}{$\mathrm{B}$} & $\mathrm{C}^{1)}$ \\
\hline Characteristic length $a^{*}$ & $50.85 \mathrm{~mm}$ & \multicolumn{2}{|c|}{$36.32 \mathrm{~mm}$} & $72.64 \mathrm{~mm}$ \\
\hline $\begin{array}{l}\text { Ratio of geometrical } \\
\text { similarity }\end{array}$ & 7 & \multicolumn{2}{|c|}{5} & 10 \\
\hline Shaft & Vertical & \multicolumn{2}{|c|}{ Horizontal } & Vertical \\
\hline Feeder & Feed pipe & \multicolumn{2}{|c|}{ Feed ring } & Feed pipe \\
\hline Feed ratio $k_{\mathrm{O}}$ & 0.20 & \multicolumn{2}{|c|}{0.19} & 0.15 \\
\hline & (Partly $0.10,0.30$ ) & & & \\
\hline Feed mass-concentration & $1.0 \%$ & \multicolumn{2}{|c|}{$1.0 \%$} & $0.5 \%$ \\
\hline \multirow[t]{2}{*}{ Feed powder } & Silica S & Silica $\mathrm{M}$ & Silica L & Polymethyl \\
\hline & (SS) & $(\mathrm{SM})$ & $(\mathrm{SL})$ & $(\mathrm{PM})^{1)}$ \\
\hline True relative density $\gamma$ & 2.2 & 2.2 & 2.2 & 1.19 \\
\hline Dynamic shape factor $\kappa$ & 1 & 1 & 1 & 1 \\
\hline Diameter range $(\mu \mathrm{m})$ & $0.1 \sim 3$ & $0.2 \sim 3.6$ & $0.2 \sim 4.8$ & $1 \sim 12$ \\
\hline Median diameter $D_{\mathrm{PM}}^{*}(\mu \mathrm{m})$ & 0.8 & 1.1 & 1.4 & 4.7 \\
\hline
\end{tabular}

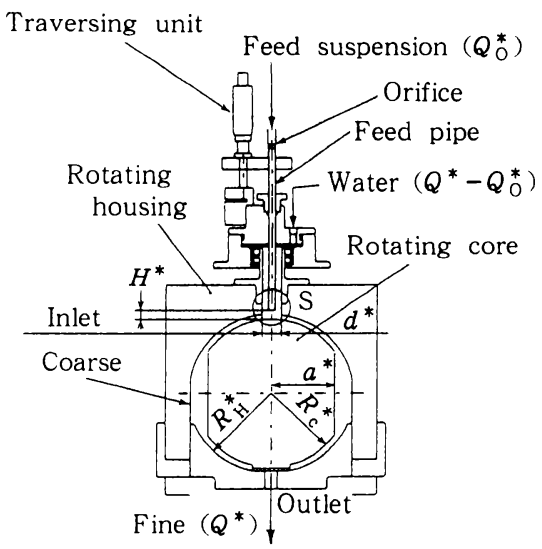

(a) Sphere-cylinder classifier A

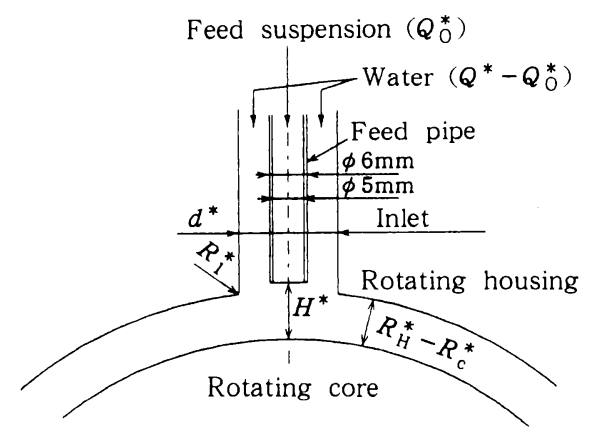

(b) Details of the feeder section $\mathrm{S}$

Fig. 1 Sphere-cylinder classifier A and details of the feeder section $S$ (vertical shaft; dimensions (units $\mathrm{mm}$ ) $: a^{*}=50.85 ; R_{\mathrm{c}}^{*}=61.53 ; R_{\mathrm{H}}^{*}=66.14$; $d^{*}=\phi 15.3 ; H^{*}=5.00 ; R_{1}^{*}=1.0$ )

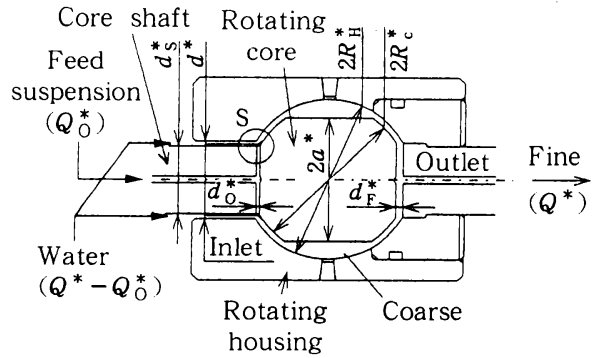

(a) Sphere-cylinder classifier B

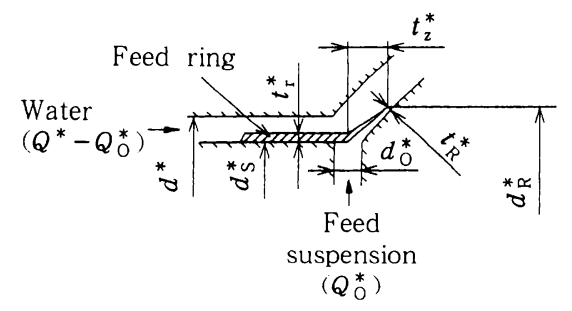

(b) Details of the feeder section $\mathrm{S}$

Fig. 2 Sphere-cylinder classifier B and details of the feeder section $S$ (horizontal shaft; dimensions (units $\mathrm{mm}$ ) : $a^{*}=36.32$; $R_{\mathrm{c}}^{*}=43.95 ; R_{\mathrm{H}}^{*}=47.25 ; d^{*}=\phi 46.0$; $d_{\mathrm{O}}^{*}=4-\phi 2.0 ; d_{\mathrm{F}}^{*}=4-\phi 4.0 ; d_{\mathrm{S}}^{*}=\phi 40.0$; $d_{\mathrm{R}}^{*}=\phi 48.0 ; t_{\mathrm{R}}^{*}=0.1 ; t_{\mathrm{z}}^{*}=3.0 ; t_{\mathrm{r}}^{*}=1.0$ )

の分級試験装置， A (Fig. 1)， B (Fig. 2)， C (既報 ${ }^{1}$ ) の Fig. 2), ならびに 4 種類の原料粉体, シリカ $\mathrm{S}$ (SS), シリカM (SM), シリカ $\mathrm{L}$ (SL), ポリメタク リル酸メチル $\left(\mathrm{PM}\right.$, 既報 $\left.{ }^{1)}\right)$ の諸元を示す。 
Table 2 Experimental results of the $50 \%$ cut size $D_{\mathrm{P} 50}^{*}$ obtained in the present and previous ${ }^{1)}$ studies under 22 test-conditions distinguished by the classifier (A, $\mathrm{B}$, and $\left.\mathrm{C}^{1)}\right)$, the feed powder (SS, SM, SL, and $\left.\mathrm{PM}^{1)}\right)$, the feed ratio $\left(k_{\mathrm{O}}=0.10\right.$, $0.15,0.19,0.20$, and 0.3$)$, the Ekman number $\left(E=(2.0 \sim 9.0) \times 10^{-6}\right)$ and the Rossby number $\left(R_{\mathrm{S}}=(2.0 \sim 22.0) \times 10^{-3}\right)$

(a) Present data

\begin{tabular}{rccccccc}
\hline $\begin{array}{r}\text { Condi- } \\
\text { tion }\end{array}$ & flassi- & Feed & \multicolumn{2}{c}{$k_{\mathrm{O}}$} & $E$ & $R_{\mathrm{S}}$ & $\begin{array}{c}D_{\text {P50 }}^{*} \\
{[\mu \mathrm{m}]}\end{array}$ \\
\hline 1 & A & SS & 0.20 & $2.0 \times 10^{-6}$ & $3.0 \times 10^{-3}$ & 0.48 & $2.00 \times 10^{8}$ \\
2 & A & SS & 0.10 & $2.0 \times 10^{-6}$ & $3.0 \times 10^{-3}$ & 0.48 & $2.00 \times 10^{8}$ \\
3 & A & SS & 0.30 & $2.0 \times 10^{-6}$ & $3.0 \times 10^{-3}$ & 0.49 & $2.00 \times 10^{8}$ \\
4 & A & SS & 0.20 & $2.0 \times 10^{-6}$ & $4.0 \times 10^{-3}$ & 0.54 & $1.50 \times 10^{8}$ \\
5 & A & SS & 0.20 & $4.0 \times 10^{-6}$ & $2.0 \times 10^{-3}$ & 0.59 & $1.50 \times 10^{8}$ \\
6 & A & SS & 0.20 & $2.0 \times 10^{-6}$ & $6.0 \times 10^{-3}$ & 0.63 & $1.00 \times 10^{8}$ \\
7 & A & SS & 0.20 & $4.0 \times 10^{-6}$ & $3.0 \times 10^{-3}$ & 0.69 & $1.00 \times 10^{8}$ \\
8 & A & SS & 0.20 & $4.0 \times 10^{-6}$ & $4.0 \times 10^{-3}$ & 0.78 & $7.50 \times 10^{7}$ \\
9 & B & SM & 0.19 & $2.0 \times 10^{-6}$ & $6.0 \times 10^{-3}$ & 0.50 & $1.00 \times 10^{8}$ \\
10 & B & SM & 0.19 & $2.0 \times 10^{-6}$ & $8.3 \times 10^{-3}$ & 0.58 & $7.23 \times 10^{7}$ \\
11 & B & SM & 0.19 & $2.0 \times 10^{-6}$ & $11.3 \times 10^{-3}$ & 0.64 & $5.30 \times 10^{7}$ \\
12 & B & SL & 0.19 & $5.4 \times 10^{-6}$ & $6.0 \times 10^{-3}$ & 0.89 & $3.71 \times 10^{7}$ \\
13 & B & SL & 0.19 & $5.4 \times 10^{-6}$ & $8.3 \times 10^{-3}$ & 1.06 & $2.69 \times 10^{7}$ \\
14 & B & SL & 0.19 & $7.0 \times 10^{-6}$ & $8.3 \times 10^{-3}$ & 1.16 & $2.07 \times 10^{7}$ \\
15 & B & SL & 0.19 & $9.0 \times 10^{-6}$ & $8.3 \times 10^{-3}$ & 1.35 & $1.61 \times 10^{7}$ \\
16 & B & SL & 0.19 & $5.4 \times 10^{-6}$ & $16.4 \times 10^{-3}$ & 1.50 & $1.36 \times 10^{7}$ \\
\hline
\end{tabular}

(b) Previous data ${ }^{1)}$

\begin{tabular}{|c|c|c|c|c|c|c|c|}
\hline $\begin{array}{l}\text { Condi- } \\
\text { tion }\end{array}$ & $\begin{array}{c}\text { Classi- } \\
\text { fier }\end{array}$ & $\begin{array}{l}\text { Feed } \\
\text { powder }\end{array}$ & $k_{\mathrm{O}}$ & $E$ & $R_{\mathrm{S}}$ & $\begin{array}{c}D_{\mathrm{P} 50}^{*} \\
{[\mu \mathrm{m}]}\end{array}$ & $C_{\mathrm{E}}$ \\
\hline 17 & $\mathrm{C}$ & PM & 0.15 & $5.0 \times 10^{-6}$ & $7.0 \times 10^{-3}$ & 3.86 & $5.42 \times 10^{6}$ \\
\hline 18 & $\mathrm{C}$ & PM & 0.15 & $5.0 \times 10^{-6}$ & $8.3 \times 10^{-3}$ & 3.93 & $4.57 \times 10^{6}$ \\
\hline 19 & $\mathrm{C}$ & PM & 0.15 & $5.0 \times 10^{-6}$ & $10.0 \times 10^{-3}$ & 3.93 & $3.80 \times 10^{6}$ \\
\hline 20 & $\mathrm{C}$ & PM & 0.15 & $7.0 \times 10^{-6}$ & $8.3 \times 10^{-3}$ & 4.40 & $3.27 \times 10^{6}$ \\
\hline 21 & $\mathrm{C}$ & PM & 0.15 & $8.0 \times 10^{-6}$ & $8.3 \times 10^{-3}$ & 4.50 & $2.87 \times 10^{6}$ \\
\hline 22 & C & PM & 0.15 & $5.0 \times 10^{-6}$ & $22.0 \times 10^{-3}$ & 6.29 & $1.73 \times 10^{6}$ \\
\hline
\end{tabular}

Fig. 1 は, 分級装置Aの本体および原料粉体分散液 供給部 S の詳細を示す。この装置は既報 ${ }^{1}$ の分級装置 C と同様の縦軸形で, Cの7/10のスケールであり, コアの円柱部分の半径 $a^{*}=50.85 \mathrm{~mm}$ および球面部分 の半径 $R_{\mathrm{c}}^{*}=61.53 \mathrm{~mm}$, 八ウジングの球面半径 $R_{\mathrm{H}}^{*}=$ $66.14 \mathrm{~mm}$ ，供給水の流入筒部の直径 $d^{*}=15.3 \mathrm{~mm}$ である。原料粉体分散液は, 分級装置 C の場合之同様 に,フィードパイプによって回転コアの軸上に供給さ れる。

Fig. 2 は, 分級装置Bの本体および原料粉体分散液 供給部 S の詳細を示す。この装置は横軸形で, 既報1) の分級装置 C $1 / 2$ のスケールである $\left(a^{*}=36.32\right.$ $\left.\mathrm{mm}, R_{\mathrm{c}}^{*}=43.95 \mathrm{~mm}, R_{\mathrm{H}}^{*}=47.25 \mathrm{~mm}\right)$ 。ただし, 供 給水の流入円筒部の直径 $d^{*}$ は, 高速回転できるよう
にコアのシャフトを流入側にもつけたため, 相似の值 の4.2倍 $\left(d^{*}=46.0 \mathrm{~mm}\right)$ とかなり大きくなっている。 この分級装置 Bでは, 原料粉体分散液が, 分級装置 $\mathrm{A}$ およびCの場合とは相違して, コアのシャフトの中空 部分から軸対称のフィードリングを介してコア側エク マン層へ直接供給される。

上述の分級装置 A, Bで用いた原料粉体は, Table 1 に示したように, 真比重 $\gamma$ が 2.2 の高純度合成球状 シリカ（アドマテックス, SO-E2 と SO-E3) の球形 粒子（動力学的形状係数 $\kappa=1$ ) であり, その粒径範 囲とメジアン径 $D_{\mathrm{PM}}^{*}$ (質量基準) がそれぞれ約 $0.1 \sim 3$ $\mu \mathrm{m}, 0.8 \mu \mathrm{m}$ のシリカS (SS) を分級装置Aで使用 し, 一方, それぞれ $0.2 \sim 3.6 \mu \mathrm{m}, 1.1 \mu \mathrm{m}$ のシリカ M (SM) ならびにそれぞれ $0.2 \sim 4.8 \mu \mathrm{m}, 1.4 \mu \mathrm{m}$ の 
シリカL（SL）を分級装置Bで使用した（これらの頻 度分布 $f_{\mathrm{O}}$ については後述のFig. 4参照)。なお，上述 のシリカの分散剂としてセルナ（中京油脂，D-305） を使用した。そして, 原料粉体分散液（分散媒は水） に対する原料粉体，分散剂の質量濃度をともに $1.0 \%$ の希薄な値とした。

なお，既報”の分級装置Cで用いた原料粉体は，真 比重 $\gamma$ が 1.19 のポリメタクリル酸メチル（積水化成 品工業, MB-4）の球形粒子で，その粒径範囲とメシ アン径は，それぞれ約 $1 \sim 12 \mu \mathrm{m} ， 4.7 \mu \mathrm{m}$ である。

分級試験の方法は既報" ${ }^{12}$ 同じで，初めに原料粉体 分散液の代わりに水を用いて, 安定な定常・軸対称 流が生成されるように八ウジング・コアの回転角速 度 $\Omega^{*}$, 貫流量 $Q^{*}$, 原料粉体分散液の流量 $Q_{0}^{*}$ の設 定, すなわち, 次式で定義されるエクマン数 $E$ ， ロス ビ一数 $R_{\mathrm{S}}$, 原料粉体分散液の流量比 $k_{\mathrm{O}}$ の設定を行 い, その後, 水から原料粉体分散液に切り換えること により，分級実験を開始し，再び水に戻すことによっ て終了する。

$$
\begin{gathered}
E=\nu^{*} /\left(\Omega^{*} a^{* 2}\right), \quad R_{\mathrm{S}}=U_{\mathrm{E}}^{*} /\left(\Omega^{*} a^{*}\right), \\
k_{\mathrm{O}}=Q_{\mathrm{O}}^{*} / Q^{*} \\
\left(U_{\mathrm{E}}^{*}=Q^{*} /\left\{4 \pi a^{*}\left(\nu^{*} / \Omega^{*}\right)^{0.5}\right\}\right)
\end{gathered}
$$

ここで, $\nu^{*}$ は流体の動粘度, $U_{\mathrm{E}}^{*}$ は厚さが $O\left(\left(\nu^{*} /\right.\right.$ $\left.\left.\Omega^{*}\right)^{0.5}\right)$ のエクマン層内の平均半径速度の概略值であ る。

本研究では, Table 2 (a) に示す 16 通りの試験条件 で分級試験を行った。試験条件は，分級装置と原料粉 体の種類ならびに原料粉体分散液の流量比 $k_{0}$, エク マン数 $E$ ， ロスビー数 $R_{\mathrm{S}}$ の值によって分類されてい る。なお，分級装置 $\mathrm{A} ， \mathrm{~B}$ において， $k_{0}$ の值を Table 2 (b) に示す既報") (分級装置C) の試験条件 之同じ 0.15 に設定すると, 微粉産物の分散液濃度が 低下して正確な粒度測定が困難であったので，分級装 置Aでは $k_{0}$ を 0.20 （ただし試験条件 2 と 3 ではそれ ぞれ 0.10，0.30)，分級装置 Bでは 0.19 のそれぞれ高 い值に設定した。表中の遠心効果パラメータ $C_{\mathrm{E}}$ につ いては, 後述する。

また，分級径を求めるのに必要となる頻度分布の 求め方も既報 ${ }^{1)}$ と同じである。まず，原料粉体，微 粉産物の各ふるい上積算分布 (質量基準) $R_{\mathrm{O}}\left(D_{\mathrm{P}}^{*}\right)$, $R_{\mathrm{F}}\left(D_{\mathrm{P}}^{*}\right)$, を光透過式の遠心沈降式粒度分布測定装置 （島津製作所， SA-CP4L）により測定し，次にこれら の測定值の近似関数を求めて, その微分値之微粉収率 $\eta_{\mathrm{F}}$ の值から各頻度分布 $f_{\mathrm{O}}\left(D_{\mathrm{P}}^{*}\right), f_{\mathrm{F}}\left(D_{\mathrm{P}}^{*}\right)$ を求めた。

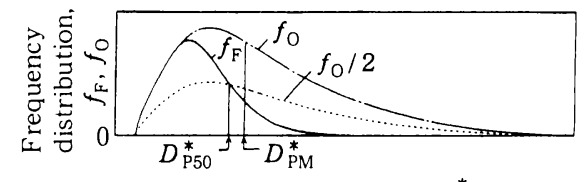

Particle diamater, $D_{\mathrm{P}}^{*}$

Fig. $350 \%$ cut size $D_{\mathrm{P} 50}^{*}$ and the median diameter $D_{\mathrm{PM}}^{*}$ of feed powder $\left(f_{\mathrm{O}}\right.$ and $f_{\mathrm{F}}$ are frequency distributions of the feed powder and the fine product, respectively)

なお，既報" ではふるい上積算分布の繰返し測定の誤 差が約 $5 \%$ 以下であったが，本報では測定に細心の 注意を払って約 $2 \%$ 以下の誤差に抑えた。

\section{2 分級試験結果}

Table 2（a）（b）には，前述の本報および既報" における 22 通りの試験条件のもとで行われた分級試 験により得られた $50 \%$ 分離粒径 (分級径) $D_{\mathrm{P} 50}^{*}$ の值 も示されている。ここで $D_{\mathrm{P} 50}^{*}$ は， Fig. 3に示すように 微粉産物の頻度分布 $f_{\mathrm{F}}\left(D_{\mathrm{P}}^{*}\right)$ の值が原料粉体の頻度分 布 $f_{0}\left(D_{\mathrm{P}}^{*}\right)$ の $50 \%$ となる粒径 $D_{\mathrm{P}}^{*}$ の值である。すな わち, $D_{\mathrm{P} 50}^{*}$ は $f_{\mathrm{F}}$ と $f_{\mathrm{O}} / 2$ の曲線の交点の粒径である。 なお，原料粉体のメジアン径 $D_{\mathrm{PM}}^{*}$ は $f_{\mathrm{O}}$ 曲線と横軸で 囲まれた面積を二分する粒径であり，分級径 $D_{\mathrm{P} 50}^{*}$ と は一致しない。

Fig. 4 (a)，(b)，(c) は, Table 2 (a) のそれぞれ 試験条件 1 8 (分級装置 $\mathrm{A}$, 原料粉体 SS)，9１1 (B, SM)， 13〜16（B, SL) で得られた微粉産物の各 頻度分布 $f_{\mathrm{F}}$ （実線）を，原料粉体の頻度分布 $f_{\mathrm{O}}$ （一点 鎖線）とその $1 / 2$ の頻度分布 $\left(f_{\mathrm{O}} / 2\right.$, 破線 $)$ ととも に示す。Fig. 4（a）において，原料粉体分散液の流 量比 $k_{\mathrm{O}}$ が一定の場合, 試験条件 $6 \rightarrow 4 \rightarrow 1$ あるいは $8 \rightarrow 7 \rightarrow 5$ の結果から, エクマン数 $E$ が一定すなわ ち回転数が一定ならば $f_{\mathrm{F}}$ の分布曲線はロスビー数 $R_{\mathrm{S}}$ の減少（貫流量の減少）とともに粒径の小さい方向に 寄ることが知られる。これにともなって，分級径 $D_{\mathrm{P} 50}^{*}\left(\right.$ 各 $f_{\mathrm{F}}$ と $f_{0} / 2$ との交点の横座標） も小さくな る。これは, 既報1 ${ }^{1}$ で報告したように，貫流量の減少 による流体抗力の減少のため, 相対的に遠心力の効果 が増大するからである。これに対して, 試験条件 $7 \rightarrow$ 3 あるいは $8 \rightarrow 4$ の結果から知られるように, $R_{\mathrm{S}}$ が 一定ならば分級径は $E$ の減少（回転数の増大）と之 もに小さくなる。これは，回転数の増大にともなう遠 心力効果の增大による。他方， $E, R_{\mathrm{S}}$ がともに一定 で $k_{0}$ の值が変化する場合は, 試験条件 $1 ， 2 ， 3$ の 結果から知られるように， $f_{\mathrm{F}}$ 曲線および分級径に大 


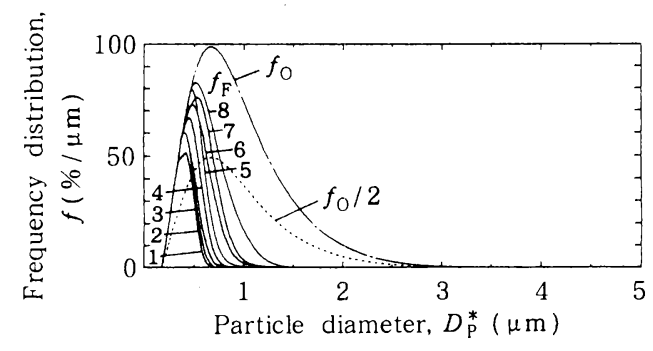

(a) Test-conditions $1 \sim 8$ (Classifier $\mathrm{A}$ $\left.\left(a^{*}=50.85 \mathrm{~mm}\right), \mathrm{SS}\right)$

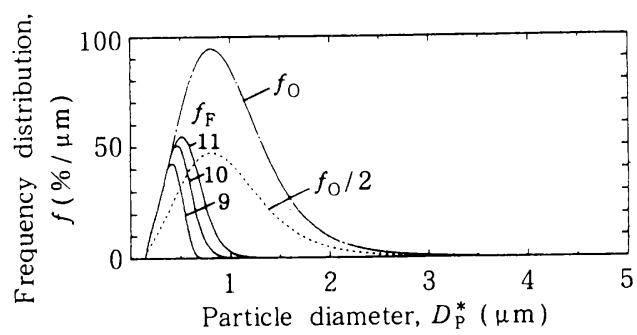

(b) Test-conditions 9 11 (Classifier $\mathrm{B}$ $\left.\left(a^{*}=36.32 \mathrm{~mm}\right), \mathrm{SM}\right)$

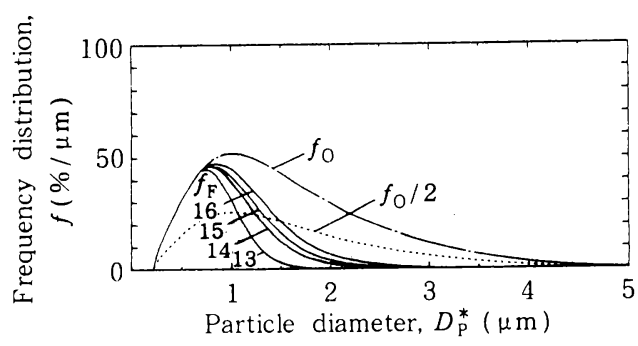

(c) Test-conditions 13 16 (Classifier B $\left.\left(a^{*}=36.32 \mathrm{~mm}\right), \mathrm{SL}\right)$

Fig. 4 Frequency distributions $f_{\mathrm{F}}\left(D_{\mathrm{P}}^{*}\right)$ of the fine products (solid lines) obtained under the various test-conditions presented in Table 2 (a) (frequency distribution $f_{\mathrm{O}}\left(D_{\mathrm{P}}^{*}\right)$ of each feed powder and its half frequency distribution $f_{\mathrm{O}}\left(D_{\mathrm{P}}^{*}\right) / 2$ are shown by dashed-anddotted and broken lines, respectively)

きな変化は見られない。

以上のFig. 4 (a) の場合とは分級機の大きさ, 原料 粉体の粒度分布が相違する Fig. 4 (b)，(c) において も， $k_{\mathrm{O}}$ が一定の場合, $E$ が一定ならば分級径は $R_{\mathrm{S}}$ の 減少とともに小さくなる（試験条件 $11 \rightarrow 10 \rightarrow 9 ）$ あ るいは， $R_{\mathrm{S}}$ が一定ならば分級径は $E$ の減少とともに 小さくなる（試験条件 $15 \rightarrow 14 \rightarrow 13 ） と い う$ 同様の結 果が得られる。

しかしながら, 上述のような考察では, Fig. 4(a), (b)，(c) にわたる分級径の変化を統一的に説明する
ことができない。そこで，次章では統一的な説明をめ ざして，粒子運動方程式に基づく理論的考察から新た な無次元パラメータの導入を試みる。

\section{3. 分級場における粒子運動とスケール則}

本研究のように，原料粉体分散液の質量濃度が希薄 $(0.5 \sim 1 \%)$ で粒子が微小 $(0.1 \sim 12 \mu \mathrm{m})$ な場合に は，流れに対する粒子運動の影響を無視することがで き，かつ粒子同士の相互干渉も無視することができる ので，流れ（非圧縮・粘性流）と粒子（単一粒子）の 運動をそれぞれ独立に解析することができる。

流れの支配方程式は，本方式の主な分級場がエクマ ン層とスチュワートソン層であると考えられるので, 次式の回転系における準剛体回転流の無次元ナヴィ エ・ストークス式および連続式で与えられる。なお， 無次元化の代表長さ（長さスケール）は，分級機の 代表長さである回転コアの円柱部分の半径 $a^{*}$ ，代表 速度（速度スケール）は前述（Eq. (1)）の $U_{\mathrm{E}}^{*}$ であ る。

$$
\begin{aligned}
& 2 \boldsymbol{k} \times \boldsymbol{U}=-\nabla p+E \nabla^{2} \boldsymbol{U} \\
& \nabla \cdot \boldsymbol{U}=0
\end{aligned}
$$

ここで $U$ は流体速度, $p$ は遠心力項と重力項を含む压 力, $\boldsymbol{k}$ は軸方向の単位ベクトルである。周知のよう に, 準剛体回転流ではロスビー数 $R_{\mathrm{S}}$ を含む慣性項 $\left(R_{\mathrm{S}} U \cdot \nabla \boldsymbol{U}\right)$ が無視されているので, 流れの無次元支 配パラメータはエクマン数 $E$ のみである。

他方, 単一粒子の有次元運動方程式は, 次式の回転 円筒座標系 $\left(r^{*}, \phi, z^{*}\right)$ におけるバセット・ブシネ スク・オセーン式で与えられる。

$$
\begin{aligned}
& \rho_{\mathrm{P}}^{*}\left(\pi D_{\mathrm{P}}^{* 3} / 6\right)\left\{\mathrm{d} \boldsymbol{V}^{*} / \mathrm{d} t^{*}+2 \Omega^{*} \boldsymbol{k} \times \boldsymbol{V}^{*}\right. \\
& \left.-\Omega^{* 2} r^{*} \boldsymbol{i}\right\} \\
= & -\left(\rho_{\mathrm{P}}^{*}-\rho^{*}\right)\left(\pi D_{\mathrm{P}}^{* 3} / 6\right) \mathrm{g} \boldsymbol{k} \\
& -3 \pi \kappa \rho^{*} \nu^{*} D_{\mathrm{P}}^{*}\left(\boldsymbol{V}^{*}-\boldsymbol{U}^{*}\right) \\
& +\rho^{*}\left(\pi D_{\mathrm{P}}^{* 3} / 6\right)\left\{\mathrm{d} \boldsymbol{U}^{*} / \mathrm{d} t^{*}\right. \\
& \left.+2 \Omega^{*} \boldsymbol{k} \times \boldsymbol{U}^{*}-\Omega^{* 2} r^{*} \boldsymbol{i}\right\} \\
& +\alpha \rho^{*}\left(\pi D_{\mathrm{P}}^{* 3} / 6\right)\left\{\mathrm{d} \boldsymbol{U}^{*} / \mathrm{d} t^{*}\right. \\
& \left.+2 \Omega^{*} \boldsymbol{k} \times \boldsymbol{U}^{*}-\mathrm{d} \boldsymbol{V}^{*} / \mathrm{d} t^{*}-2 \Omega^{*} \boldsymbol{k} \times \boldsymbol{V}^{*}\right\}
\end{aligned}
$$

ここで, $\rho_{\mathrm{P}}^{*}, D_{\mathrm{P}}^{*}, \boldsymbol{V}^{*}, \kappa, \alpha$ は粒子のそれぞれ真密 度, 球相当径 (供試球形粒子の直径), 速度, 動力学 的形状係数 (球形粒子では 1), 仮想質量係数 (球形 粒子では0.5）であり， $g$ は重力加速度， $t^{*}$ は時間， $i$ は半径方向単位ベクトルである。なお, 粒子は微小で あるので, 流体抗力 $\boldsymbol{F}_{\mathrm{d}}^{*}$ を次式のようにストークス抵 
抗 $\left(C_{\mathrm{d}}\right.$ は抗力係数, $R e_{\mathrm{p}}$ は粒子レイノルズ数) と拉 き，バセット項（粒子速度が変化することによって流 体が得る総運動量の時間的変化）を無視している。

$$
\begin{aligned}
\boldsymbol{F}_{\mathrm{d}}^{*} & =C_{\mathrm{d}}\left\{\rho^{*}\left(\boldsymbol{V}^{*}-\boldsymbol{U}^{*}\right)\left|\boldsymbol{V}^{*}-\boldsymbol{U}^{*}\right| / 2\right\}\left(\pi D_{\mathrm{P}}^{* 2} / 4\right) \\
& =3 \pi \kappa \rho^{*} \nu^{*} D_{\mathrm{P}}^{*}\left(\boldsymbol{V}^{*}-\boldsymbol{U}^{*}\right) \\
\left(C_{\mathrm{d}}\right. & \left.=24 \kappa / R e_{\mathrm{p}}, R e_{\mathrm{p}}=\left|\boldsymbol{V}^{*}-\boldsymbol{U}^{*}\right| D_{\mathrm{P}}^{*} / \nu^{*}\right)
\end{aligned}
$$

本研究で対象とする微小な粒子の運動の時間スケー ルは, 流机によって決定づけられるので, 粒子運動の 時間スケールは流れの時間スケール $a^{*} / U_{\mathrm{E}}^{*}$ と同じで あると考えられる。すなわち，粒子運動の長さスケー ルと速度スケールは，流れのそれぞれ長さスケール $a^{*}$ ，速度スケール $U_{\mathrm{E}}^{*}$ と同じであると考えられる。 そこで，これらのスケールにより Eq. (4) の無次元化 を行う之, 次式の単一粒子の無次元運動方程式が得ら れる。

$$
\begin{aligned}
& \gamma\left\{\mathrm{d} \boldsymbol{V} / \mathrm{d} t+2 \boldsymbol{k} \times \boldsymbol{V} / R_{\mathrm{S}}-r \boldsymbol{i} / R_{\mathrm{S}}^{2}\right\} \\
&=-(\gamma-1) \boldsymbol{k} / F_{\mathrm{r}}^{2} \\
&-18 \kappa(\boldsymbol{V}-\boldsymbol{U})|\boldsymbol{V}-\boldsymbol{U}| /\left(D_{\mathrm{P}} R e_{\mathrm{p}}\right) \\
&+\left\{\mathrm{d} \boldsymbol{U} / \mathrm{d} t+2 \boldsymbol{k} \times \boldsymbol{U} / R_{\mathrm{S}}-r \boldsymbol{i} / R_{\mathrm{S}}^{2}\right\} \\
&+\alpha\left\{\mathrm{d} \boldsymbol{U} / \mathrm{d} t+2 \boldsymbol{k} \times \boldsymbol{U} / R_{\mathrm{S}}-\mathrm{d} \boldsymbol{V} / \mathrm{d} t\right. \\
&\left.-2 \boldsymbol{k} \times \boldsymbol{V} / R_{\mathrm{S}}\right\}
\end{aligned}
$$

上式は，無次元粒径 $D_{\mathrm{p}}$ の粒子運動（粒子速度 $\boldsymbol{V}$ ) が 粒子の真比重 $\gamma$, 動力学的形状係数 $\kappa$, 仮想質量係数 $\alpha$ ，およびロスビー数 $R_{\mathrm{S}}$, フルード数 $F_{\mathrm{r}}\left(=U_{\mathrm{E}}^{*} /\right.$ $\left.\left(a^{*} g\right)^{0.5}\right)$, 粒子レイノルズ数 $R e_{\mathrm{p}}$, ならびに流体速 度 $\boldsymbol{U}$ （すなわち $\boldsymbol{U}$ を決定するエクマン数 $E$ ）により 支配されていることを表している。

上式において，前述の分級試験条件を考慮すれば, 支配パラメータについて, さらに以下のことが導かれ

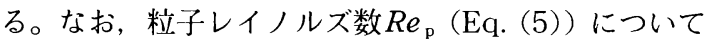
は, 次の変形式を用いる。

$$
R e_{\mathrm{p}}=\left|\boldsymbol{V}^{*}-\boldsymbol{U}^{*}\right| D_{\mathrm{P}}^{*} / \nu^{*}=|\boldsymbol{V}-\boldsymbol{U}| D_{\mathrm{P}} R_{\mathrm{S}} / E
$$

まず，Table 1，Table 2, Fig. 1，Fig. 2の分級試 験・装置の条件より

$$
\begin{aligned}
& D_{\mathrm{P}}=(0.02 \sim 1.7) \times 10^{-4}, \gamma=1.19 \sim 2.2, \\
& \kappa=1, \alpha=0.5, F_{\mathrm{r}}=(0.1 \sim 2.6) \times 10^{-1}, \\
& R_{\mathrm{S}}=(2.0 \sim 22.0) \times 10^{-3}, E=(2.0 \sim 9.0) \times 10^{-6}, \\
& r=0.15 \sim 1.1
\end{aligned}
$$

が得られ，また粒子速度 $\boldsymbol{V}$ と流体速度 $U$ については

$$
\begin{aligned}
& |\mathrm{d} \boldsymbol{V} / \mathrm{d} t| \sim 10^{\circ},|\boldsymbol{V}| \sim 10^{\circ}, \\
& |\mathrm{d} \boldsymbol{U} / \mathrm{d} t| \sim 10^{\circ},|\boldsymbol{U}| \sim 10^{\circ}
\end{aligned}
$$

と推測できるので，Eq. (6) の各項を次式の [ ] に 示すように見積もることができる。

$$
\begin{aligned}
\underline{\gamma} & \left(\mathrm{d} \boldsymbol{V} / \mathrm{d} t+2 \boldsymbol{k} \times \boldsymbol{V} / R_{\mathrm{S}}-r \boldsymbol{i} / R_{\mathrm{S}}^{2}\right) \\
& {[1 \sim 2]\left[(0.1 \sim 2) \times 10^{3}\right] \underline{\left[(0.004 \sim 6) \times 10^{5}\right]} } \\
=- & (\gamma-1) \boldsymbol{k} / F_{\mathrm{r}}^{2} \\
& {\left[(0.003 \sim 6) \times 10^{3}\right] } \\
\frac{-}{} & 18 \kappa(\boldsymbol{V}-\boldsymbol{U}) E /\left(R_{\mathrm{S}} D_{\mathrm{P}}^{2}\right) \\
\frac{\left[(0.000006 \sim 2) \times 10^{10}|\boldsymbol{V}-\boldsymbol{U}|\right]}{+} & \left(\mathrm{d} \boldsymbol{U} / \mathrm{d} t+2 \boldsymbol{k} \times \boldsymbol{U} / R_{\mathrm{S}}-r \boldsymbol{i} / R_{\mathrm{S}}^{2}\right) \\
& {[1]\left[(0.09 \sim 1) \times 10^{3}\right] \underline{\left[(0.003 \sim 3) \times 10^{5}\right]} } \\
+ & \alpha\left(\mathrm{d} \boldsymbol{U} / \mathrm{d} t+2 \boldsymbol{k} \times \boldsymbol{U} / R_{\mathrm{S}}-\mathrm{d} \boldsymbol{V} / \mathrm{d} t\right. \\
& {\left[5 \times 10^{-1}\right]\left[(0.5 \sim 5) \times 10^{2}\right]\left[5 \times 10^{-1}\right] } \\
- & \left.2 \boldsymbol{k} \times \boldsymbol{V} / R_{\mathrm{S}}\right) \\
& {\left[(0.5 \sim 5) \times 10^{2}\right] }
\end{aligned}
$$

上式の各項の見積もり結果より, 下線部の遠心力項之 流体抗力項が支配的で, その他の項は無視できること が分かる。したがって, 粒子運動を決定づけるこれら の支配項のつりあいから，

$$
\begin{aligned}
\boldsymbol{V}-\boldsymbol{U} & =(\gamma-1) D_{\mathrm{P}}^{2} r \boldsymbol{i} /\left(18 \kappa E R_{\mathrm{S}}\right) \\
& =C_{\mathrm{E}} D_{\mathrm{P}}^{2} r \boldsymbol{i} / 18
\end{aligned}
$$

が得られる。ただし

$$
C_{\mathrm{E}}=(\gamma-1) /\left(\kappa E R_{\mathrm{S}}\right)
$$

は, 密度 $\rho^{*}$ の流体中における真密度が $\rho_{\mathrm{P}}^{*}$, 粒径が $D_{\mathrm{P}}^{*}$ の単一粒子に作用する遠心力と流体抗力の比を特 徵づける無次元パラメータであり, 本論文ではこれを 遠心効果パラメータと呼ぶ。Eq. (11) は, 流線から の粒子のずれを引き起こす無次元相対速度 $\boldsymbol{V}-\boldsymbol{U}$ が, 無次元粒径 $D_{\mathrm{P}}$ と上述の遠心効果パラメータ $C_{\mathrm{E}}$ によ り支配されていることを表している。よって， $C_{\mathrm{E}}$ は 分級径を支配する重要なパラメー夕であると考えられ る。

Fig. 5 は, Table 2 の分級試験条件 1 22 で得られ た分級径 $D_{\mathrm{P} 50}^{*}$ の無次元值 $D_{\mathrm{P} 50}$ を遠心効果パラメー夕 $C_{\mathrm{E}}$ に対して示す。実線で示すように, $D_{\mathrm{P} 50}$ は $C_{\mathrm{E}}$ の 一意的な関数として定まる。すなわち, 無次元分級径 は, 原料粉体の粒度分布（粒径範囲やメジアン径， 重力の方向に対する回転軸の方向（縦軸・横軸）や, 原料粉体分散液の供給方法（Fig. 1に示したフィード パイプによるか，あるいはFig. 2のフィードリングに 


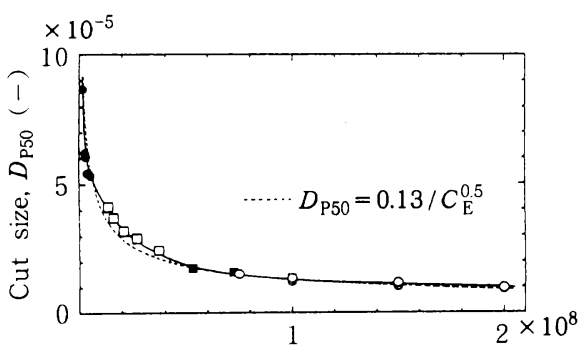

Centrifugal-effect parameter, $C_{\mathrm{E}}(-)$

Fig. 5 Relationship between the dimensionless $50 \%$ cut size $D_{\mathrm{P} 50}$ and the centrifugal-effect parameter $C_{\mathrm{E}}$ under the test-conditions $1 \sim 22$ in Table 2 , guided by a solid line ( $1 \sim 8$ : classifier A $\left(a^{*}=50.85 \mathrm{~mm}\right)$, SS ;

9 11: classifier B $\left(a^{*}=36.32 \mathrm{~mm}\right)$, SM ; $\square$ 12 16 : classifier B $\left(a^{*}=36.32 \mathrm{~mm}\right)$, SL ; - 17 22 : classifier C $\left(a^{*}=72.64 \mathrm{~mm}\right), \mathrm{PM}$; broken line is given by Eq. (14))

よるか)，供給割合（原料粉体分散液の流量比 $k_{0}$ ）の 多少の相違にも依存せず，遠心効果パラメータ $C_{\mathrm{E}}$ の みにより一意的に決まることが明らかになった。

一方，図中の破線は，粒子運動方程式Eq. (5) にお いて, 粒子に作用する遠心力の大きさと流体抗力の大 きさの比が一定であるときの粒径が分級径を与えると 仮定した場合に得られる関係

$$
\begin{aligned}
& \left\{\left(\rho_{\mathrm{P}}^{*}-\rho^{*}\right)\left(\pi D_{\mathrm{P} 50}^{* 3} / 6\right) \Omega^{* 2} r^{*}\right\} \\
& /\left\{3 \pi \kappa \rho^{*} \nu^{*} D_{\mathrm{P} 50}^{*}\left|V^{*}-\boldsymbol{U}^{*}\right|\right\} \\
= & C_{\mathrm{E}} D_{\mathrm{P} 50}^{2} r /(18|\boldsymbol{V}-\boldsymbol{U}|)=\mathrm{const} . \\
& \therefore D_{\mathrm{P} 50} \sim C_{\mathrm{E}}^{-0.5}
\end{aligned}
$$

において, 比例定数を実験値との最小自乗近似から求 めた 0.13 としたときの次の関係を示す。

$$
D_{\mathrm{P} 50}=0.13 / C_{\mathrm{E}}^{0.5}
$$

上述の実験結果は，この関係によくあっている。同様 に $0 \%, 100 \%$ 分離粒径の $D_{\mathrm{P} 0}, D_{\mathrm{P} 100}$ についても $C_{\mathrm{E}}$ に対してプロットすれば，これらの值が $D_{\mathrm{P} 50}$ と同様 に $C_{\mathrm{E}}$ の一意的な関数として定まる。ただし， $D_{\mathrm{P} 0}$ ， $D_{\mathrm{P} 100}$ の実験值のバラッキは $D_{\mathrm{P} 50}$ の場合よりも大き い。

以上の考察より，本方式における主な分級場はエク マン層とスチュワートソン層であり，粒子運動の長さ スケールと速度スケールは，流れのそれらと同じもの であると考えてよいことが分かった。

\section{4. スケールアップについて}

本章では，前章で得たスケール則に基づいて，本分

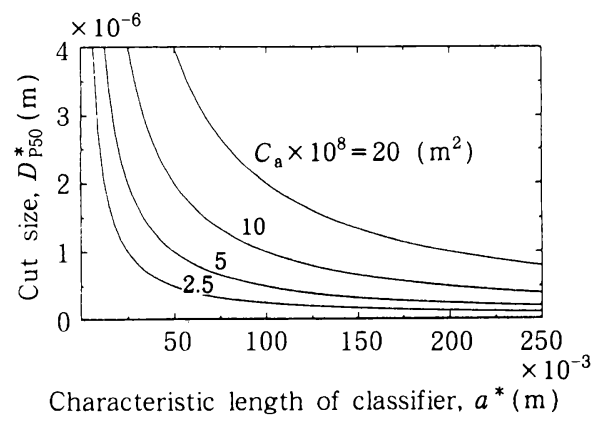

Fig. 6 Dependence of the $50 \%$ cut size $D_{\mathrm{P} 50}^{*}$ on the characteristic length $a^{*}$ of the classifier

級方式をスケールアップした場合の有次元の分級径 $D_{\mathrm{P} 50}^{*}$ の変化について考察する。有次元の分級径は, Eq. (14) より次式のように得られる。

$$
D_{\mathrm{P} 50}^{*}=C_{\mathrm{a}} / a^{*}
$$

ただし

$$
\begin{aligned}
C_{\mathrm{a}}= & 0.13 a^{* 2} / C_{\mathrm{E}}^{0.5} \\
= & 0.065 \times \nu^{* 0.25} \kappa^{0.5} Q^{* 0.5} \\
& /\left\{\pi^{0.5}(\gamma-1)^{0.5} \Omega^{* 0.75}\right\}
\end{aligned}
$$

Fig. 6 は，分級機の代表長さ（回転コアの円柱部分の 半径) $a^{*}$ を増大させたときの分級径 $D_{\mathrm{P} 50}^{*}$ の変化を示 す。Eq. (15) から明らかなように, Eq. (16) の $C_{\mathrm{a}}$ を一定に保つスケールアップの場合, 例えば同一の 原料粉体 $\left(\kappa, \gamma\right.$ が同じ) および溶媒 $\left(\nu^{*}\right.$ が同じ) に 対して $Q^{* 0.5} / \Omega^{* 0.75}$ を一定に保つ場合には，分級径 $D_{\mathrm{P} 50}^{*}$ は分級機の代表長さの $a^{*}$ の増大に反比例して減 少する。

なお，分級機を運転するのに必要な動力について は, Figs. 1 と 2 から知られるように, 分級機の流入 側の半球において分級機から流体へ伝達されるトルク が流出側の半球において回収できるので，ベアリン グでの摩擦トルクのみを考慮すればよいと考えられ る。

\section{5. 結言}

水に希薄濃度で分散させた原料粉体の微粒子を，準 剛体回転流を用いて分級する方式について，以下のス ケール則を明らかにした。粒子運動の長さスケールと 速度スケールは，流れのそれらと同じものである。そ して, 長さスケール $a^{*}$ に対する分級径 $D_{\mathrm{P} 50}^{*}$ の比す なわち無次元分級径 $D_{\mathrm{P} 50}^{*} / a^{*}$ は，分級機の回転軸の 方向や原料粉体の粒度分布およびその供給方法が相違 
しても，遠心効果パラメータ $C_{\mathrm{E}}$ のみの関数で与えら れることを明らかにした。

本研究は, 文部省科学研究費補助金・基盤研究 C2
（H11～12 年度 11650172）の援助を受けた。ここに 付記し謝意を表す。

\section{Nomenclature}

$a^{*} \quad$ : radius of the cylindrical part of the rotating core (characteristic length)

$C_{\mathrm{a}} \quad$ : quantity given by Eq. (14)

: drag coefficient of the partic

particle (Eq. (5))

$C_{\mathrm{E}}$ : centrifugal-effect parameter (Eq. (12)) (-)

$d^{*}$ : diameter of the inlet

$D_{\mathrm{P}}^{*} \quad$ : sphere equivalent diameter, $D_{\mathrm{P}} a^{*}$

$D_{\mathrm{PM}}^{*}$ : median diameter of the feed powder (mass base)

$(\mathrm{m})$

$D_{\mathrm{PN}}^{*}: N \%$ cut size, $D_{\mathrm{PN}} a^{*}(N=0,50,100)$

$E \quad$ : Ekman number (Eq. (1))

$f\left(D_{\mathrm{P}}^{*}\right) \quad$ : frequency distribution (mass base, $f_{\mathrm{O}}=-\mathrm{d} R_{\mathrm{O}} / \mathrm{d} D_{\mathrm{P}}^{*}, f_{\mathrm{F}}=-\eta_{\mathrm{F}} \mathrm{d} R_{\mathrm{F}} / \mathrm{d} D_{\mathrm{P}}^{*}$,

$\left.f_{\mathrm{C}}=-\left(1-\eta_{\mathrm{F}}\right) \mathrm{d} R_{\mathrm{C}} / \mathrm{d} D_{\mathrm{P}}^{*}=f_{\mathrm{O}}-f_{\mathrm{F}}\right)$

$\boldsymbol{F}_{\mathrm{d}}^{*}$ : drag acting on the particle (Eq. (5))

$F_{\mathrm{r}} \quad$ : Froude number, $U_{\mathrm{E}}^{*} /\left(a^{*} g\right)^{0.5}$

$g \quad$ : acceleration of gravity

$(-)$

$(\boldsymbol{i}, \boldsymbol{j}, \boldsymbol{k}) \quad$ : unit vectors in the rotating cylindrical coordinate system

$k_{\mathrm{O}}$ : feed-suspension ratio, $Q_{\mathrm{O}}^{*} / Q^{*}$

$p \quad$ : dimensionless pressure reduced by the centrifugal force and gravity $\left\{p^{*}-\rho^{*} \Omega^{* 2} r^{* 2}+\rho^{*} g z^{*}\right\} /$

$\left(\rho^{*} \Omega^{*} a^{*} U_{\mathrm{E}}^{*}\right)$

$\left(\mathrm{m}^{-1}\right)$

(N)

$(-)$

$\left(\mathrm{m} / \mathrm{s}^{2}\right)$

$(-)$

$(-)$

$Q^{*}:$ through-flow rate

$Q_{O}^{*}:$ flow rate of the feed suspension $\left(\mathrm{m}^{3} / \mathrm{s}\right)$

$\left(r^{*}, \phi, z^{*}\right)$ : rotating cylindrical coordinate system (radial, azimuthal, and axial coordinates),

$$
\begin{gathered}
\left(r a^{*}, \phi, z a^{*}\right) \\
R\left(D_{\mathrm{P}}^{*}\right) \quad \text { oversize distribution (mass base) }(\mathrm{m},-, \mathrm{m})
\end{gathered}
$$

$R_{\mathrm{c}}^{*}$ : radius of the spherical part of the rotating core (m)

$R e_{\mathrm{p}}$ : particle Reynolds number (Eq. (7)) (-)

$R_{\mathrm{H}}^{*}$ : radius of the spherical part of the rotating housing

$(\mathrm{m})$

$R_{\mathrm{S}} \quad$ : Rossby number (Eq. (1)) (-)

$t^{*} \quad:$ time, $t a^{*} / U_{\mathrm{E}}^{*}$

$\boldsymbol{U}^{*}$ : flow velocity vector, $\boldsymbol{U} U_{\mathrm{E}}^{*}(\mathrm{~m} / \mathrm{s})$

$U_{\mathrm{E}}^{*}$ : characteristic velocity (Eq. (1)) (m/s)

$\boldsymbol{V}^{*}$ : particle velocity vector, $\boldsymbol{V} U_{\mathrm{E}}^{*}(\mathrm{~m} / \mathrm{s})$

$\alpha$ : virtual-mass coefficient of the particle (0.5 for a spherical particle) (-)

$\gamma \quad:$ true relative density ratio, $\rho_{\mathrm{P}}^{*} / \rho^{*} \quad(-)$

$\eta_{\mathrm{F}} \quad$ : yield of fine product (mass-base) (-)

$\kappa \quad$ : dynamic shape factor ( 1 for a spherical particle) (-)

$\nu^{*}$ : kinematic viscosity of fluid $\left(\mathrm{m}^{2} / \mathrm{s}\right)$

$\rho^{*}:$ density of fluid $\left(\mathrm{kg} / \mathrm{m}^{3}\right)$

$\rho_{\mathrm{P}}^{*}:$ true density of the particle $\left(\mathrm{kg} / \mathrm{m}^{3}\right)$

$\Omega^{*}$ : angular velocity of the rotating housing and core

$(\mathrm{rad} / \mathrm{s})$

Subscripts

$\mathrm{C}, \mathrm{F}$ : concerning the coarse and fine products respectively

$\mathrm{O}$ : concerning the feed suspension

$\mathrm{P} \quad$ : concerning the particle

Superscripts

* : variables with dimension corresponding to the dimensionless ones

\section{References}

1) Nakabayashi, K and Y. Tsuchida : "Accurate Wet-type Centrifugal Classification using an Almost Rigidly Rotating Flow - Classification Principle and Performance of the Batch-type Classification-", J. Soc. Powder Technol., Japan, 36, 881-890 (1999)

2) Nakabayashi, K and Y. Tsuchida: “Accurate Wet-type Centrifugal Classification using an Almost Rigidly Rotating Flow - Classification Principle and Performance of the Continuous-type Classification -", $J$. Soc. Powder Technol., Japan, 36, 891-896 (1999)

3) Ito, M. : "Cut Size Estimation in Centrifugal Air
Classifiers", J. Soc. Powder Technol., Japan, 28, 488-494 (1991)

4) Ito, M. : "Cut Size Simulation of a Centrifugal Air Classifier - The Influence of Relative Velocity, Shape and the Agglomerate of Particles - ", J. Soc. Powder Technol., Japan, 31, 92-99 (1994)

5 ) Fuyuki, T., Y. Yamada, H. Yoshida and K. Iinoya : “Scale-up Performance of Dry Classification Cyclones-Evaluation by Different Particle Size Measurement Instruments - ", J. Soc. Powder Technol., Japan, 32, 526-532 (1995) 